\title{
Chelsea Charms: ciało kuriozalne jako marka
}

\section{Wojciech KLIMCZYK}

\begin{abstract}
Streszczenie
Chelsea Charms twierdzi, że jest posiadaczką największego na świecie sztucznego biustu, który czyni ją swoistą gwiazdą medialną, pieczołowicie dbającą o wizerunek, którego wyznacznikiem są właśnie ogromnych rozmiarów piersi. W kulturowym sensie między jej wizerunkiem a jej piersiami można postawić znak równości, co pozwala mówić o procesie budowania swoistej marki, której „logo” staje się prezentowany na różne sposoby biust.

W niniejszym tekście przyglądam się sposobom, w jaki tworzy się medialna figura „kobiety o największym (powiększonym) biuście na świecie", w świetle teorii globalnego przemysłu kulturowego Celii Lury i Scotta Lasha oraz kulturowej roli fetyszyzmu w dobie nowoczesności według Hartmuta Böhmego. Podejmuję próbę zdekonstruowania marki „Chelsea Charms” w kontekście współczesnej kultury wizerunku, która żywi się transformacją ciała jak żadna inna. Stawiam też kluczowe pytanie: czy sztuczne ciało przekłada się automatycznie na sztuczną tożsamość, czy też relacja między nimi jest znacznie bardziej skomplikowana, a jej rekonstrukcja może przyczynić się do zrozumienia współczesnych strategii tożsamościowych nie tylko w analizowanym przypadku? Odpowiedź jest paradoksalna: właśnie poprzez kuriozalność swojego ciała, staje się Chelsea Charms modelową przedstawicielką kultury wirtualności, której fundacyjnymi mitami są jednostkowa sprawczość, kreatywna wolność i plastyczny charakter egzystencji, w tym ciała.
\end{abstract}

Słowa kluczowe: globalny przemyst kulturowy, fetyszyzm, kultura wizerunku, wizerunek, Chelsea Charms, implanty, ciato

Wojciech KLIMCZYK socjolog z wykształcenia, z zamiłowania bliższy kulturoznawstwa. Autor książek Erotyzm ponowoczesny, Wizjonerzy ciała. Panorama wspótczesnego teatru tańca oraz Wirus mobilizacji. Taniec a ksztaltowanie się nowoczesności (1455-1795), tomy 1-2. E-MAIL: wojciech.klimczyk@uj.edu.pl 


\section{I}

W 2010 roku w londyńskiej galerii White Cube Marc Quinn, artysta zaliczany do nurtu YBA (Young British Artists), będącego jednym z przykładowych „przedmiotów” globalnego przemysłu kulturowego analizowanych przez Celię Lury i Scotta Lasha (2011, 91-114), zaprezentował cykl rzeźb Allanah, Buck, Catman, Chelsea, Michael, Pamela and Thomas. Tematem wystawy byli ludzie, którzy manipulują swoim ciałami: transseksualne gwiazdy porno, mężczyzna, który zaszedł w ciążę, człowiek pragnący maksymalnie upodobnić się pod względem fizycznym do kota, ale też celebryci głównego nurtu: Michael Jackson i Pamela Anderson. W wywiadzie dla Guardiana, zapytany, czy chciał stworzyć ponowoczesną wersję freak show, artysta zarzekał się, że wręcz przeciwnie - jego rzeźby nie traktują o dziwactwie, ale o człowieczeństwie (Hattenstone 2010).

W niniejszym artykule pragnę pójść śladem tego stwierdzenia i przyjrzeć się w szczegółach jednej z wyrzeźbionych przez Quinna postaci - modelce i tancerce egzotycznej Chelsea Charms, która zdobyła sobie miano kobiety o największym na świecie sztucznym biuście. Tym, co mnie szczególnie interesuje, nie jest jednak osobista historia Charms, którą można zapewne potraktować jako współczesną wersję figury ludzkiej osobliwości w typie człowieka-gumy czy kobiety-syreny, znanej z wędrownych pokazów święcących szczególne triumfy w XIX wieku (Adams 2001; Bogdan 1990; Chemers 2008; Durbach 2010; Thomson 1996) (choć brak w tle figury Chelsea obrotnego impresaria i trudno dopatrzeć się tragicznego wydźwięku jej historii, które upodobniałyby ją do tych ukazanych choćby w Dziwolagach Toda Browninga [1932] czy Człowieku słoniu Davida Lyncha [1980]). Nie psychologiczna czy psychoanalityczna analiza tego jednostkowego przypadku jest celem rozważań ${ }^{1}$. Dużo bardziej interesuje mnie to, co, jak się wydaje, przyciągnęło do Charms Quinna, artystę bardzo sprawnie obracającego się w świecie, który markę uczynił głównym obiektem kulturowych przepływów, markę będącą czymś znacznie bardziej skomplikowanym niż znak towarowy. Artyści z nurtu YBA, jak pokazują Lash i Lury, zdobyli sobie wyjątkowo eksponowaną pozycję w świecie sztuki współczesnej, doskonale rozumiejąc, że

1 Pójście tą ścieżką wymagałoby odbycia pogłębionego wywiadu z Charms, a także odpowiedniego przygotowania merytorycznego. Dostępne w serwisie YouTube wywiady sugerują, że początkowo Charms była osobą nieśmiałą, czującą się niepewnie przed kamerą (patrz choćby Charms 2010a), co może świadczyć o kompensacyjnym charakterze jej cielesnej transformacji, ale bynajmniej nie musi. 
nie ma już istotnej różnicy między życiem a dziełem, między egzystencją a reprezentacją, bynajmniej nie dlatego, że egzystencja staje się całkowicie zapośredniczona (model przemysł kulturalnego w ujęciu Adorna i Horkheimera), ani też dlatego, że reprezentacja się egzystencjalizuje (model sztuki dla sztuki), ale ponieważ, jak zauważają autorzy Globalnego przemystu kulturowego, reprezentacja i egzystencja nakładają się na siebie w procesie medializacji rzeczy i urzeczowienia mediów. W dobie kulturowej hegemonii wirtualności redefiniowana jest stopniowo relacja człowieka i mediów. Imperatywem staje się maksymalna intensywność kreowanego przedmiotu kulturowego, potraktowanie go jako zdarzenia. Takim przedmiotem-zdarzeniem jest marka „Chelsea Charms”. Jej anatomię pragnę zrekonstruować, by, niczym w soczewce, skupić podstawowe tendencje kultury wirtualności, której podstawowym przejawem są procesy umarkowienia nie tylko towarów, ale też egzystencji.

\section{II}

Inspiracją metodologiczną niniejszych rozważań jest postawiona w 1927 roku teza Sigfrieda Kracauera otwierająca jego Ornament z ludzkiej masy: „Miejsce, jakie dana epoka zajmuje w procesie historycznym, można określić znacznie trafniej na podstawie analizy jej powierzchownych, mało znaczących zjawisk, niż w oparciu o jej własne sądy o sobie, które jako wyraz tendencji czasu nie są wiążącym świadectwem przy całościowym jej ujęciu. Pozwalają one ze względu na swój nieświadomy charakter na bezpośredni dostęp do podstawowych treści epoki. Ich poznanie łączy się natomiast z interpretacją owych sądów. Podstawowe treści epoki i jej nie dostrzegane odruchy objaśniają się wzajemnie" (Kracauer 1987, 11).

Między innymi dzięki Kracauerowi bardzo ostrożnie już dzisiaj, jako kulturoznawcy, pochodzimy do nazywania pewnych zjawisk kulturowych powierzchownymi i mało znaczącymi, ale też nie o ocenę społecznej wagi analizowanego przypadku w niniejszych rozważaniach chodzi, lecz o dostrzeżenie systemowych implikacji tego, co potocznie funkcjonuje na poziomie medialnej sensacji: jako temat programów telewizji śniadaniowej, filmików kompilacyjnych w serwisie YouTube, stron internetowych sytuujących się gdzieś między generującą ogromny ruch w sieci twardą pornografią filmową a staromodną erotyką fotograficzną, konsumowaną przez „tradycyjnego 
widza" ${ }^{2}$. Kracauer w swoim eseju, gdy przyglądał się zsynchronizowanym ruchom scenicznych chorus girls, to próbował zrozumieć modus operandi kapitalizmu przemysłowego swoich czasów, w którym dokonywała się powszechna tayloryzacja procesów produkcji, przekładająca się na dyscyplinowanie jak najbardziej materialnych ciał. Na podobnej zasadzie chciałbym, na drodze prowadzonych tu rozważań, odsłonić cielesny aspekt procesów, o których piszą Lury i Lash w odniesieniu do kapitalizmu zwanego kognitywnym, gospodarki opartej na wiedzy, gospodarki intensywności, w których również zachodzą procesy dyscyplinowania jak najbardziej materialnych ciał, ale na zasadzie ich wirtualizacji (Lash i Lury 2011, 27).

W tekście Kracauera szczególnie ważne jest dla mnie spostrzeżenie, idące wbrew typowemu już dla jego czasów „zdroworozsądkowemu” (i seksistowskiemu) poglądowi, że odsłonięcie kobiecego ciała ma charakter erotyczny. Jak podkreślał, „Masowe poruszanie się dziewcząt zawisa [...] w próżni, jest to system linii, nie wyrażający już niczego erotycznego, wyznaczający co najwyżej miejsce erotyki” (Kracauer 1987, 12)3. Chcę pokazać, że w przypadku operacji, jakim poddała się Chelsea Charms, również nie chodzi w pierwszym rzędzie o erotyzację, choć oczywiście fetyszystyczny erotyzm jest jednym z korzeni jej popularności, ale bynajmniej nie tym najmocniej eksponowanym. Dążeniem nie jest w przypadku zainteresowania Charms, jak w pornografii, zaspokojenie pożądania, a raczej, jak w filmie animowanym, fantazmat transformacji. W rzeczy samej, tak jak w przypadku analizowanych przez Kracauera Tiller Girls, choć, rzecz jasna, w zupełnie innym kontekście ekonomiczno-społecznym, mamy do czynienia z erotycznie pustym gestem racjonalnego, niemal abstrakcyjnego obnażenia czystej wielkości. Fotograficzne akty Charms cechuje zaskakująca rzeczowość, pewnego rodzaju banalność, brak typowego dla przekazów pornograficznych sosu wyuzdania. Jej

2 Charms zdecydowanie mocniej jest obecna w sieci za pośrednictwem zdjęć niż filmów, choć i filmy zamieszcza na swojej stronie, z której są one pobierane i redystrybuowane przez fanów za pomocą popularnych serwisów z różnego rodzaju erotyką, przede wszystkim twardą, w rodzaju xvideos.com. Nie znalazłem jednak żadnego filmu z Charms, który można byłoby nazwać twardą pornografią.

3 Nie znaczy to, że Kracauer zaprzeczał, iż dla kogoś Tiller Girls mogą być podniecające. Podkreślał jedynie, że istotą choreografii skomponowanej z odsłoniętych fragmentów kobiecego ciała jest ornament jako abstrakcyjny wzór, a więc przejaw typowego dla nowoczesności dążenia do racjonalizacji. Bardzo podobnie sprawa przedstawia się w przypadku Charms, choć tutaj kontekst seksualny jest wyraźniej obecny. Absurdalna wielkość jej biustu sprawia, że przekroczone zostają granice erotycznego podziemia i figura trafia do mediów głównego nurtu. To tam staje się ornamentem, czymś wyabstrahowanym właśnie. 
gigantyczny biust jest prezentowany tak, jak kulturyści prezentują muskulaturę albo sportowcy swoje techniczne umiejętności. Mamy do czynienia raczej z pracą nad sobą niż z uwodzeniem, z dziełem tworzonym, a nie prawdą odkrytą. Wszystko odbywa się na powierzchni, choć w odniesieniu do bardzo specyficznie pojętej transcendencji.

W duchu ogólnej metody Kracauera szukania w tym, co mało znaczące, przejawów działania najbardziej podstawowej logiki systemu społecznokulturowego, w dalszej części tekstu przyjrzę się sposobom prezentowania Chelsea Charms w różnego typu medialnych przekazach (programy telewizyjne, strony internetowe, filmy w serwisie Youtube), by wychwycić ogólną zasadę tworzenia ucieleśnionego wizerunku w kulturze wirtualności. Analiza na poziomie pojęciowym prowadzić będzie od fetyszyzmu (ujmowanego kulturoznawczo raczej, niż psychoanalitycznie) jako gruntu, na którym figura, taka jak Charms, może się narodzić, do specyficznie współczesnej wariacji na jego temat, którą nazywam ciałem kuriozalnym. Między fetyszyzmem a kuriozalnością zachodzi relacja, której zrozumienie wydaje mi się kluczowe, jeśli chcemy wniknąć w istotę kultury wirtualności. Jej uchwycenie będzie moim punktem dojścia. Zacznę jednak od możliwie syntetycznej charakterystyki samej marki „Chelsea Charms”.

\section{III}

Piersi Charms nie są dziełem natury, lecz chirurga. Już to skłania do potraktowania jej medialnej figury jako zespołowej kreacji. Kuszące byłoby w związku z tym spojrzenie na emblemat wirtualnego przedmiotu kultury, którym się zajmujemy, czyli marki „Chelsea Charms” (prawdziwe imię i nazwisko osoby ucieleśniającej figurę, pozostaje, przypomnijmy, publicznie nieznane), z perspektywy kulturowej roli designu w dobie nowoczesności. Piersi Charms powstały wszak w efekcie projektu, który zasadniczo ma charakter podobny do projektu wyjątkowo oryginalnego domu, wykonanego na życzenie nietypowego klienta. Modelka nie jest tutaj autorem dzieła, a jego fundatorem. Inwestorem zamawiającym dzieło. Nie wiemy, na ile ostateczny kształt „logo” marki jest wynikiem jej wyraźnych sugestii, a na ile chirurgowi (projektantowi) dano wolną rękę. Pozostawiam ten wątek nierozwiniętym ${ }^{4}$, gdyż schodzi on w medialnych opowieściach na jej temat na

4 Tak, jak możliwą analizę z perspektywy genderowej, gdyż nie mamy danych, by stwierdzić, czy chirurgiem plastycznym wszczepiającym implanty Charms był mężczyzna, czy 
drugi plan. Skoro Chelsea całkowicie identyfikuje się ze stworzoną kreacją, liczą się nie techniczne szczegóły jej powstawania ${ }^{5}$, ale jej, wydawałoby się prosty, efekt - nikt nie ma większego biustu niż Chelsea. ${ }^{6}$ Dzięki niemu Charms jest osobą bardzo popularną, nie tylko w świecie erotyki. Gości $\mathrm{w}$ programach telewizyjnych i radiowych w mediach głównego nurtu. ${ }^{7} \mathrm{~A}$ przede wszystkim ma swój fandom, którego twórczość można podziwiać na jej stronie internetowej www.chelseacharms.com i który towarzyszy jej na co dzień na Twitterze, gdzie aktywność Charms śledzi ponad 270 tys. użytkowników (Charms 2019a). Kuszące byłyby badania ukazujące charakter tego fandomu, niemniej w związku z tym, że interesują mnie wirtualne wyobrażenia, również ten kontekst pozostawiam z boku. Oczywiście, to ludzie powołują do życia Chelsea Charms jako przedmiot kulturowy, nie czynią tego jednak w warunkach dowolnych i dlatego skupiam się nie na nadawcy komunikatu (wspomagana przez chirurga/projektanta Charms jako osoba), ani też nie na jego głównym odbiorcy (zseksualizowane męskie [czy aby na pewno?] spojrzenie), ale na wykraczającej poza erotyczny kontekst marce, rozumianej jako wartość znakowa figury „Chelsea Charms” zestawialna z innymi tego typu markami, choćby tymi będącymi bohaterami prac Quinna: Catmanem, Pamelą Anderson i Michaelem Jacksonem.

kobieta. Z feministycznej perspektywy ma to oczywiście duże znaczenie, gdyż w pierwszym przypadku mamy do czynienia z kontynuacją niechlubnej tradycji modelowania kobiecego ciała przez męskie spojrzenie, a nawet po prostu ręce. Jednakże nawet w przypadku kobiety-chirurga można byłoby zadać pytanie o charakter modelującego gestu: na ile był on poczyniony w duchu „siostrzanego” wsparcia dla działania mającego na celu społecznoekonomiczną emancypację poprzez gest wyzyskania systemowych uwarunkowań dla własnych celów, a na ile bezrefleksyjnym (albo cynicznym) dopasowaniem się do męskich standardów uprzedmiotowiających kobiecość w postaci monstrualnych piersi jako pobudzającego męskie pożądanie fetysza.

5 Co odróżnia projekt Charms choćby od performansów Orlan, w których operacja plastyczna, jako proces transformacji, postawiona była na pierwszym planie (zob. m.in. Ryczek 2006, 177-191).

${ }^{6}$ W ostatnich latach niemiecka modelka erotyczna Beshine stara się odebrać Charms tytuł posiadaczki największych piersi na świecie. Jednak mnie nie interesuje tu wynik rywalizacji, a sama figura „kobiety o największym biuście”, która wyłania się z medialnego dyskursu o ponowoczesnych przygodach ludzkiego ciała. Zresztą sam wynik nie jest przesądzony. Co często podkreślane przez samą Charms, jej piersi wciąż rosną, w związku z zastosowaniem dziś już zakazanej technologii.

7 Dla jej szerszej rozpoznawalności ważny był występ w programie „This Morning” brytyjskiej stacji ITV, porównywalnym z polskim „Dzień dobry TVN” (This Morning 2011). 
Dla zseksualizowanego spojrzenia Charms może w rzeczy samej być jedynie towarem, który pragnie się skonsumować, gdy jednak trafia do telewizji śniadaniowej, zaczyna funkcjonować zgodnie z odmienną logiką: „Marka działa dzięki wartości znakowej konstytuującej [...] różnicę tworzoną w [...] relacji z marką. Wartość użytkowa i forma towarowa są właściwościami produktu. Wartość znakowa i marka nie są właściwościami produktu, są właściwościami doświadczenia [kursywa w oryg.]. Doświadczenia usytuowanego na powierzchni, czy też w interfejsie komunikacji zachodzącej między konsumentem a marką [...]. To doświadczenia ma wydarzeniowy charakter" (Lash i Lury 2011, 18).

\section{IV}

Następująca charakterystyka Chelsea jest bardzo wymowna z punktu widzenia proponowanych w niniejszym tekście rozważań:

Piersi Chelsea zaczęły rozwijać się w młodym wieku. Zanim została model-

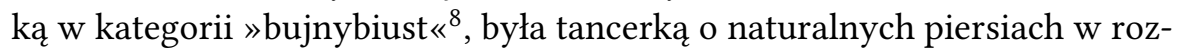
miarze D. Podjęła jednak decyzję, by zostać modelką [a także tzw. feature dancer, czyli główną gwiazdą wieczorów ze striptizem, wymienianą z nazwiska w materiałach promocyjnych] i poddała się operacji wszczepienia implantów. Początkowo powiększyła piersi do rozmiaru E a potem do $\mathrm{HH}$ za pomocą techniki implantów solankowych. Po tych zabiegach pojawiła się na okładkach magazynów takich jak »Buxotica «, »SCORE« czy »Hustler Busty Beauties «, specjalizujących się w pokazywaniu modelek o dużych piersiach. Około roku 2000 Chelsea przeszła do historii, gdy zdecydowała się na wszczepienie polipropylenowych implantów strunowych. Tego typu implanty podrażniają tkankę, co powoduje stopniowy wzrost piersi. W przypadku Chelsea oznaczało to powiększenie rozmiaru do 153xxx a następnie aż do 177xxx. ${ }^{9} \mathrm{Z}$ powodu swoich dużych piersi Chelsea jest nazywana »Królową Bujnego Biustu « i »Kobietą o Największych Piersiach na Świecie«. [...] Z powodu specyfiki zastosowanych implantów piersi Chelsea wciąż rosną (około 25 milimetrów na miesiąc)" (Boobpedia 2019).

Tym, co uderza przede wszystkim w przytoczonej charakterystyce, jest utożsamienie postaci Chelsea z jej piersiami oraz epicka skala opisu,

8 Świat erotyki, internetowej, ale nie tylko, rządzi się logiką klasyfikacji i akomodacji do zróżnicowania konsumenckich gustów (Klimczyk 2008, 220-223).

9 Strona Charms podaje, iż obecny ich rozmiar to (w calach) 207Zzz-23-34 (Charms 2019b). 
wyrażająca się w zwrotach, takich jak: „przeszła do historii”, „królowa biustu” czy „największe piersi świata”. Ta „epickość” postaci Charms zafascynowała również Quinna, który stwierdził w cytowanym wywiadzie, iż „z tymi absurdalnie wielkimi piersiami i całkowicie naturalną twarzą jest jak halucynacja”. Czy wydała mu się piękna? Na to pytanie artysta odpowiedział, że „jest to specyficzny rodzaj piękna, w pewnym sensie klasyczny - jak gdyby Wenus z Willendorfu ożyła” (Hattenstone 2010). To ostanie porównanie jest szczególnie interesujące, gdyż wskazuje na to, że można popatrzeć na Charms jak na specyficznie pojmowany tradycyjny wzór. W interpretacji Quinna ogromny rozmiar jej piersi przywołuje ideał witalności i obfitości, charakterystyczny już dla paleolitycznych kultów matriarchalnych (Krzak 2007, 127-128). W tym ujęciu Charms jawi się jako uosobienie odwiecznego marzenia o kobiecej płodności. Mnie jednak interesuje spojrzenie na Chelsea nie tyle jak na archetyp, co skrajnie nowoczesny przykład aktywnego stosunku człowieka do własnego ciała.

Na swojej stronie, tłumacząc decyzję o radykalnym zwiększeniu rozmiarów biustu, Charms pisze: „it's fun to be different [fajnie jest być innym]” (Charms 2019b). W podobnym tonie wypowiada się, występując w mediach głównego nurtu. Chelsea, wszczepiając sobie implanty i wkraczając na drogę kariery kobiety o największym biuście na świecie, zaprezentowała się więc nie tylko jak strategicznie myśląca bizneswoman (inwestycja w implanty najpewniej szybko się zwróciła), ale i osoba podążająca za kulturowym ideałem - chęcią wyróżnienia się z tłumu, bycia jedynym w swoim rodzaju. To czyni ją nie tylko częścią kulturowego freak show (pokazu dziwactw), który trwa od wielu wieków i nie jest czymś z gruntu nowoczesnym, ale też modelową przedstawicielką stricte nowoczesnej kultury wizerunku, a więc kimś, paradoksalnie, doskonale sformatowanym do wymogów świata, w którym żyjemy.

\section{V}

By przyjrzeć się procesom konstytuowania się medialnego wizerunku (a więc i marki) Chelsea Charms, proponuję wyjść od tezy Hartmuta Böhmego, który stwierdził, że fetyszyzm jest zjawiskiem z gruntu nowoczesnym (Böhme 2012). Tradycyjnie pokutował pogląd, że w kulturze europejskiej pojawił się on z zewnątrz, gdy nasi przodkowie odkryli (na Czarnym Lądzie i nie tylko) tajemnicze, bałwochwalcze kulty przedmiotów obdarzanych przez 
„tubylców” ogromnymi mocami. Böhme pokazuje jednak w szczegółach, iż teza o tym, że Europejczycy jedynie „odkryli” fetyszyzm, a więc że jest on wynalazkiem egzotycznym, opiera się na tendencyjnym uproszczeniu. Gdy przyjrzymy się bliżej opowieściom kolonizatorów, odkrywamy, że nie tyle obserwowali oni fetyszyzm, co „nadpisywali” go na niezrozumiałych dla nich praktykach. Prowadzi to niemieckiego teoretyka kultury do stwierdzenia, że w gruncie rzeczy to nie tubylcy zainfekowali Europę fetyszyzmem, ale że jest on zjawiskiem z gruntu europejskim, którego korzeni szukać należy, według Böhmego, w chrześcijaństwie, przede wszystkim w kulcie relikwii. „Oto jak pisze - Afryka w nas samych, na długo przed tym, zanim została odkryta” (Böhme 2012, 157).

Po szczegóły historii kształtowania się fetyszyzmu jako europejskiego stosunku do rzeczy odesłać wypada do Fetyszyzmu i kultury. Dla proponowanych tu rozważań ważna jest przede wszystkim ogólna diagnoza, którą zawiera to znakomite studium: „fetyszyzm stał się w nowoczesnych społeczeństwach zjawiskiem powszechnym i nie sposób już zamknąć go w piwnicy, gdzie wraz z subkulturami tworzył niegdyś osobne królestwo cieni” (Böhme 2012, 446). Böhme bynajmniej nie ubolewa nad tym stanem rzeczy. Wręcz przeciwnie, postuluje, by odczarować fetyszyzm. By odejść od prostego piętnowania go jako aberracji, co samo w sobie ma cechy fetyszyzmu, na rzecz zrozumienia fetyszystycznego charakteru nowoczesności. Böhme pisze, że konieczna jest „świadomość wielowymiarowości fetyszystycznego obiektu. Dzięki temu może się odstonić poliwalentna, semantycznie naddeterminowana, przedmiotowo dowolna (polimorficzna), funkcjonalnie wieloraka, genetycznie multikazualna, typologicznie i fenomenologicznie nieskończenie bogata, procesualna natura fetyszyzmu" (Böhme 2012, 406, kursywa w oryginale). Staję na tym samym stanowisku, gdy rekonstruuję poniżej utożsamiony w zasadzie z figurą Chelsea Charms fetysz jej silikonowych piersi w jego kulturowym aspekcie, jako wizualnej reprezentacji marki funkcjonującej na globalnym rynku.

\section{VI}

Czym dokładnie jest fetysz? W klasycznej antropologii społecznej zajmującej się „egzotycznymi” praktykami religijnymi przyjęto, iż fetysze to „rzeczy mające nierzadko jakąś figuratywną formę. Fetysz składa się z dwóch elementów: (1) duchowej siły, tzn. mocy sprawczej, którą można [...] traktować 
jako dynamistyczną, magiczną, demoniczną, spirytualistyczną bądź manistyczną, oraz (2) materialnego obiektu zawierającego tę siłę [...] Niektóre fetysze mogą nią dysponować »same z siebie«; zazwyczaj jednak wytworzenie fetysza wiąże się z uroczystą konsekracją, dzięki której specjalni eksperci wprowadzają »moc «, »siłę« lub »ducha« w rzecz, tak, iż zyskuje ona zdolność sprawczą (którą trzeba rytualnie odnawiać)" (Böhme 2012, 170). Mówiąc syntetycznie, w fetyszu spotykają się: rzecz (w przypadku Chelsea sztuczny biust) + siła (jednostkowa wolność i kreatywność) + performans (medialna kariera Charms). Jest on kulturowym przedmiotem, gdyż zakłada nieustanne operacje dokonywane na materialnym substracie, prowadzące do poczucia mocy udzielającego się tym, którzy wchodzą w kontakt $\mathrm{z}$ fetyszyzowaną rzeczą.

Wydaje się, że mamy w przypadku kultu fetysza do czynienia ze sztandarowym przykładem mechanizmu alienacji opisanego w XIX stuleciu, najpierw przez Feuerbacha a potem Marksa. Fetyszyzm jest możliwy jedynie w społeczeństwie, które jest owładnięte rzeczami, a więc w społeczeństwie materialistycznym, które równocześnie nie wyzwoliło się z tęsknoty za transcendencją. Takie właśnie jest społeczeństwo kapitalistyczne, w którym przedmioty żyją własnym życiem, niejako wbrew postępującej racjonalizacji kultury, na co wskazał już Kracauer. Podkreślmy za Böhmem ten właśnie wymiar fetyszyzmu: „Ich [fetyszy] działanie ma charakter performatywny: dysponują własną agency, mocą której aktywizują w sobie siły. Są uprzedmiotowionymi agentami mocy" (Böhme 2012, 173). W takim kontekście biust Charms wydaje się dominować nad jej osobą.

Agency (sprawstwo) w nowoczesnej teorii społecznej przypisywane jest ludzkim podmiotom, staje się nawet rodzajem naczelnej charakterystyki ludzkiego bytu ${ }^{10}$, jednakże w zjawisku fetyszyzmu dochodzi do przeniesienia go na przedmioty. Czy zatem Böhme się ostatecznie myli? Bynajmniej, gdyż aktu przeniesienia dokonują poszczególne jednostki, a więc „moc” przedmiotu jest mocą przenoszącego agency podmiotu. Fetyszyzm należy w związku z tym spróbować zrozumieć nie jako wyraz fałszywej świadomości, jak

\footnotetext{
${ }^{10}$ Choćby u Anthony'ego Giddensa, wpływowego teoretyka społecznego, autora głośnej pracy Nowoczesność i tożsamość. „Ja” i społeczeństwo w epoce późnej nowoczesności (Giddens 2001), do której powrócę w końcowej partii tekstu. Na jednostkowe sprawstwo kładą nacisk także inni autorzy. Zgodnie, jak Zygmunt Bauman, z ogólnym kierunkiem Giddensowskich analiz, ale i polemizując z nimi, jak choćby Margaret Archer w dziele Człowieczeństwo. Problem sprawstwa (Archer 2013, tyt. oryg. Being Human: The Problem of Agency).
} 
chce tego marksizm czy część psychoanalityków ${ }^{11}$, ale operację kulturową, w którą zaangażowane są refleksyjne jednostki. Zjawisko fetyszyzacji jest zespoleniem jednostki z przedmiotem, które zachodzi z inicjatywy tej pierwszej w środowisku i zgodnie $\mathrm{z}$ regułami narzuconymi przez kontekst kulturowy. Mamy zatem do czynienia z aktywną równoważnością podmiotu i przedmiotu, co przykład Chelsea Charms wydatnie ukazuje - choć w społecznym odbiorze piersi poprzedzają osobę (czy też osoba zredukowana jest do piersi), to jednak piersi są dziełem osoby, jej reprezentantem i to osoba czerpie z nich korzyści. Dlatego też znaczącym uproszczeniem, by nie powiedzieć uprzedzeniem, jest postrzeganie fetyszysty jako bezbronnej ofiary fetysza. Związek między jednostką a przedmiotem, zapośredniczony przez zindywidualizowany performans i kulturowo definiowaną, ale jednostkowo ucieleśnianą moc, jest subtelny, co dostrzegła już Melanie Klein: „fetysz nie jest $w$ petni ani obiektem obdarzonym jaźnia, ani jej w petni pozbawionym. Jest osobą-rzeczą. [...] To obiekt łagodzący lęk, dający opiekę i zapewniający integralność ciała" (za Böhme 2012, 182). Idąc tym tropem w zasadzie powinniśmy powiedzieć, że fetysz to nie obiekt, a działanie (act), stała praca nad redukowaniem lęków i nad własnym ciałem, mająca dać jednostce poczucie mocy, czyli właśnie sprawstwa ${ }^{12}$.

\section{VII}

Jeśli intuicje Böhmego są słuszne, a więc jeśli fetyszyzm nie jest jedynie szkodliwą aberracją, ale systemowo funkcjonalną strategią zyskiwania przez jednostki poczucia mocy, to musi mieć wymiar nie tylko jednostkowy, ale też kulturowy. Innymi słowy, jest możliwa do odtworzenia społeczna rola fetyszy. By uczynić krok na drodze budowania takiej teorii, odwołam się do spostrzeżeń francuskiego antropologa Maurice'a Godeliera, wedle którego „Społeczeństwo ludzkie wyprowadza swoją egzystencję z dwóch źródeł - jednym z nich jest wymiana i umowa, drugim - wszystko pozostałe, co

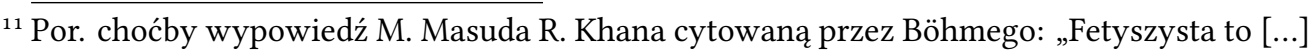
człowiek, który ma złudną pewność dostępu do magicznego obiektu i bezwzględnego posiadania go, jak również możliwości jego kontroli” (Böhme 2012, 403, wyróżnienie dodane).

${ }^{12}$ Pomocny w rozwinięciu emancypacyjnej teorii operacji plastycznych dokonywanych przez Charms mógłby być słynny esej Donny Haraway Manifest cyborgów: nauka, technologia ifeminizm socjalistyczny lat osiemdziesiątych (Haraway 2003). Jednakże nigdzie nie znalazłem danych wskazujących, by sama Charms postrzegała swoją kreację jako przejaw feministycznej postawy. 
nie podlega umowie i opiera się na przekazie. Społeczeństwo porusza się na swoich dwóch nogach, opiera się na dwóch podstawach, a obie [są] równie potrzebne i żadna nie może istnieć, jak tylko przez drugą. A zatem zawsze w społeczeństwie znajdą się sprawy, które wymykają się umowie, które nie są negocjowalne, które sytuują się poza wzajemnością" (Godelier 2010, 48). Nie inaczej jest oczywiście w społeczeństwie kapitalistycznym, także w dobie kulturowej hegemonii wirtualności. Choć z pozoru opiera się ono na czystych przepływach, na racjonalności kalkulacyjnej, rachunku zysków i strat, to jednak także nowoczesna gospodarka potrzebuje zewnętrznej, zmitologizowanej gwarancji: „nawet w kapitalizmie, jak sądzimy, muszą istnieć obszary święte, substancjalne, otoczone aurą, dzięki którym zasada wymiany towarowej, a wraz z nią desubstancjalizacja, desakralizacja $\mathrm{i}$ »deauratyzacja « zyskują ów szeroki zasięg tak przecież charakterystyczny dla nowoczesności. W ramach kapitalistycznego obiegu towarów nic nie ma już »substancji«, ponieważ istnieje coś, co jest wyłącznie substancją" (Böhme 2012, 272-273). Tym czymś, co jest substancją, co niejako gwarantuje sensowność wymiany, albo inaczej: jest atraktorem wciągającym jednostki w rynkowe gry, w konsumpcję dóbr, jest spektakularność (maksymalnie spotęgowana „różnica”, by sięgnąć do słownika Lasha i Lurry) przedmiotów, którą ucieleśnia fetysz ${ }^{13}$.

Życie społeczne w dobie kapitalizmu ma dwa wymiary. Pierwszym jest racjonalnie kontrolowana wymiana, którą rządzi zasada porównywalności i w której potrzebny jest zmysł przedsiębiorczości. Drugi to wymiar (post)auratyczny, w którym panuje zasada indywidualizacji (Benjamin 1996, 201-239). W związku z tym musimy mówić o dwóch aspektach rzeczy, a wśród nich przede wszystkim fetyszy (którymi w zasadzie mogą stać się i stają się dowolne rzeczy): ekonomicznym i auratycznym. Ten drugi został ciekawie zarysowany przez Böhmego, którego opis postaram się rozwinąć.

W Fetyszyzmie i kulturze czytamy:

Fetyszyzm towarowy [jest] siłą napędową, dzięki której gotowości do płacenia nie ograniczają racjonalność i stan niemożności płacenia, lecz wola i pragnienie stopienia się z obietnicą, jaką niesie towar - i chęć płacenia

\footnotetext{
${ }^{13}$ Przy okazji omówienia teorii fetyszyzmu towarowego zaproponowanej przez Marksa, Böhme konstatuje: „»Fetysz « to metaforyczna formuła na fascynujący i zagadkowy, nieprzejrzysty i wszechobecny, zawieszony pomiędzy naturą a maszynerią, boskością a materialnością pozór kapitalizmu. Inaczej mówiąc: »fetysz « to formuła ujmująca całość wszelkich procesów semiotycznych, w których artykułuje się i uobecnia funkcjonowanie kapitału." (Böhme 2012, 295). W zasadzie to samo można by powiedzieć o współczesnej marce.
} 
za to. O ile akt kupna jakiejś rzeczy regulowany jest przez kod płacić/nie płacić, o tyle dynamikę kupna określa aura otaczająca towar, zdefiniowana w ramachopozycji przyjemność/nieprzyjemność, uczestnictwo/nieuczestnictwo, szczęście/nieszczęście, piękno/niepiękno, sens/nonsens czy wręcz można by rzecz - byt/niebyt. Opozycje te nie wywodzą się z systemu ekonomicznego. Przyjemność, szczęście, uczestnictwo, piękno, sens, byt - to jakości, które towar, o ile jest fetyszem, rzekomo ucieleśnia, choć w istocie znajdują się one poza nim. Tym samym towar jako fetysz zyskuje osobliwie podwójny status, równocześnie rzeczy i symbolu, immanencji i transcendencji (Böhme 2012, 261).

Ten drugi aspekt wyraża pojęcie marki.

\section{VIII}

Kultura współczesna, kultura wirtualizacji, nie jest bynajmniej kulturą bez transcendencji. Ta ostatnia nie znika z przestrzeni społecznej, pomimo procesów laicyzacji i racjonalizacji życia postępujących w społeczeństwach Zacho$\mathrm{du}$. To, co transcendentne, czyli nie podlegające de facto wymianie, a jedynie przez nią komunikowane, to aura, czyli ulotna rozkosz konsumowania, przeżycie zmysłowe, które towar obiecuje, pożądanie przezeń symbolizowane.

Transcendencja w społeczeństwie konsumpcyjnym jest wpleciona w codzienność na zasadzie obietnicy tego, co, za Georges'em Bataillem, nazwać można luksusem. Pasi Falk pisze, że u Bataille'a luksus nie jest rozumiany jako „wyprodukowana pozostałość czy nadwyżka mierzona zgodnie z postulowaną normą »koniecznego «, ale transgresyjne dążenie człowieka i ludzkiej kultury do wyjścia poza Porządek.” (Falk 1994, 97). Luksus to, słowami samego Bataille'a, uczestnictwo w rytuałach zatraty, zbytku, części przeklętej, a więc doświadczenie bujności życia, jego intensywności, obfitości (Bataille 2002). To właśnie tęsknota za nim napędza konsumpcję, tworząc jej zewnętrze.

W takim środowisku fetysz zostaje obdarzony zadaniem aktualizowania transcendencji, materializowania pożądania, reprezentowania tego, co luksusowe, nadmierne, nie dające się do końca utowarowić. Nie oznacza to oczywiście, że fetysze są odporne na procesy utowarowienia. Chodzi jedynie o to, że komunikacja przy ich pomocy nie daje się sprowadzić do rynkowej wymiany. Fetysze obdarzone są naddatkiem znaczenia, który nie daje się skomercjalizować. Przykład Chelsea Charms jest tu wymowny. Jej piersi 
(a więc logo wirtualnej marki) to z jednej strony towar, który sprzedawany jest na rynku za pośrednictwem pokazów tańca erotycznego, za które Charms dostaje wynagrodzenie, i sprzedawanych przez nią zdjęć, filmów oraz różnego typu gadżetów (łącznie z używanymi częściami garderoby). Z drugiej jednak strony Charms bardzo wyraźnie dba o to, żeby jej piersi nie były wyłącznie towarem. Wyrazem tej niezgody jest przede wszystkim decyzja, by nie wejść do świata twardej pornografii ${ }^{14}$. Towarzyszy temu intrygujący image dziewczyny z sąsiedztwa, prezentowany w wywiadach dla mediów głównego nurtu, podczas których modelka jawi się jako sympatyczna, uprzejma i - choć zabrzmi to paradoksalnie - całkowicie zwyczajna. Tę zwyczajność eksponują nagie zdjęcia Charms, które najczęściej nie przypominają wcale tych z pornograficznych magazynów czy nawet Playboya, ale wyglądają jak fotografie zamieszczane masowo na portalach społecznościowych typu Facebook, z tą różnicą, że najważniejszym ich bohaterem są gigantyczne piersi. Wielkość tych ostatnich nie jest w gruncie rzeczy obojętna dla dążenia, by nie utowarowić do końca własnego ciała. Całkowicie nienaturalny gigantyzm sprawia, że biust Charms staje się jedyny w swoim rodzaju, nieporównywalny z innymi, niewymienialny, czyli niemożliwy do całkowitego utowarowienia. W ten sposób Charms otacza specyficzna aura - jest wirtuozem swojej dziedziny, darzonym nie tylko naddatkiem uwagi, ale też podziwem. ${ }^{15}$

\section{IX}

Aura, o której wspomina Böhme, w kontekście nowoczesnego kapitalizmu może być opisana przy pomocy pojęcia marki (brand). Marka nasyca towar specyficzną dla niej aurą, czyni przedmiot wyjątkowym w oparciu o logikę różnicy, wyrażoną choćby w określeniu „największy (powiększony) biust na świecie”. Dlatego marka jest intensywna, nie daje się precyzyjnie wymierzyć. Jest bytem, w stosunku do którego towary, choćby produkowane

${ }^{14}$ Najbardziej pikantnymi przedstawieniami, jakie można znaleźć w sieci, są obrazy mężczyzny pieszczącego biust Chelsea, względnie zdjęcie Charms z wibratorem albo obnażającej wargi sromowe.

${ }^{15} \mathrm{~W}$ wywiadach z Charms powtarza się często motyw wysiłku, jaki nieustannie musi ona wkładać w performowanie wizerunku kobiety o największych piersiach świata - szczególnie podkreśla się konieczność reżimu treningowego wzmacniającego mięśnie pleców (Charms 2010b). Wysiłek ten przekłada się na podziw wyrażany przez osoby rozmawiające z Chelsea. 
przez jednostkę i innych aktorów społecznych obrazy tej jednostki oferowane na sprzedaż, okazują się wtórne: obraz to jedynie zmienna odsyłająca do wizerunku. „Marki mogą przybierać formę bytów rozciągłych, ale same są intensywnościami. Marki są w pewnym sensie wirtualne. Jako byty wirtualne mogą aktualizować się w wielu przedmiotach. Ale uczucie, doświadczenie marki, pozostaje w nich takie samo" (Lash i Lury 2011, 28). Chelsea Charms jako marka, jej auratyczny wizerunek, aktualizuje się w zamieszczanych w internecie filmach i zdjęciach, programach publicystycznych, w których bierze udział, sztuce fanowskiej, a nawet w sprzedawanych on-line używanych stanikach. Jednakże figura Charms nie daje się sprowadzić do żadnej z tych rzeczy. Być może da się nawet argumentować, że jej realny, silikonowy biust jedynie aktualizuje wyobrażony, wirtualny biust, który ma cechy mityczne - jest symbolem plastyczności egzystencji, będącej jednym z fundancyjnych mitów globalnego przemysłu kulturowego.

Zasadą rynkowej gry w dobie kapitalizmu wirtualnego jest, co pokazali Lash i Lurry, nie wymienialność towarów (jak było to w tradycyjnym kapitalizmie rządzonym przez zasadę produkcji), ale różnica między towarami, dążenie do ich wzajemnej nieprzekładalności: „to cecha dystynktywna, różnica, jest źródłem wartości: źródłem wytwarzającym wartość dodatkową marki. Cecha decydująca o tym, że produkt daje się odróżnić od innych, funkcjonuje [...] poza dziedziną poszczególnych produktów i ma swoje umocowanie w sferze wyobraźni czy raczej w relacji między produktem (bądź serią produktów) a wyobraźnią. Znaki towarowe [a więc i marki - przyp. aut.] zajmują zatem przestrzeń skondensowaną, przestrzeń różnicy jako takiej. Empiryczny przepływ rzeczy, z którymi się stykamy, jest w części generowany przez tę wirtualną przestrzeń symboli. Symbole te nie są rozciągłe, nie reprezentuja przedmiotu: one konstytuują jego istotę." (Lash i Lury 2011, 261). Piersi Chelsea Charms traktowane jako symbol dosłownie „robią różnicę", wyróżniają ją z tłumu, czynią symbolem, są sposobem wyrażenia unikalnej tożsamości w warunkach całkowitej uległości systemowym imperatywom: plastyczności, gotowości do pracy nad sobą, otwartości.

\section{$\mathrm{X}$}

Obrane przez Charms strategie brandingu są, jak pokazaliśmy, całkowicie uzasadnione z punktu widzenia kultury doby hegemonii wirtualności, opartej na imperatywie nieskończonej kreatywności, elastyczności i jednostkowej odpowiedzialności, ale też niezwykle ulotnej, nie gwarantującej 
bezpieczeństwa, zmuszającej do coraz radykalniejszych gestów tożsamościowych, bo tylko one zapewniają kulturową widzialność.

Anthony Giddens syntetycznie wyraził charakter współczesnej egzystencji, pisząc:

Pojęcie stylu życia nabiera w warunkach nowoczesności szczególnego znaczenia. Wraz ze słabnącym oddziaływaniem tradycji i rosnącym udziałem dialektycznego współoddziaływania globalności i lokalności w rekonstytuowaniu życia codziennego, jednostki są zmuszone dokonywać wyborów tożsamościowych spośród różnorakich opcji. Oczywiście występują też przeciwstawne, standaryzujące tendencje. Ich najwyraźniejszym chyba przejawem jest urynkowienie, ponieważ kapitalistyczna produkcja i dystrybucja stanowią rdzeń instytucji nowoczesności. Jednakże z uwagi na „otwarty” charakter życia społecznego, zwielokrotnienie kontekstów działania i różnorodność ośrodków „władzy” rośnie znaczenie wyboru stylu życia w konstruowaniu własnej tożsamości i organizowaniu codziennej aktywności. (Giddens 2001, 8-9).

Posiadanie największych piersi świata jest z pewnością wyrazistym przykładem wyboru specyficznego stylu życia, stylizacji własnej egzystencji. Chelsea Charms operuje tym stylem świadomie, co więcej, wyobraża sobie jego zmianę, o czym świadczą jej pojawiające się w wywiadach deklaracje, że kiedyś usunie implanty. Mamy do czynienia z nowoczesną refleksyjnością, z wieloaspektowym wyborem tożsamościowym. Ale nie tylko.

Wielu autorów pisze dziś o ciele jako projekcie (Giddens 2001, 137-142; Bauman 1995; Featherstone 2008, 109-117; podsumowanie w Klimczyk 2008, 97-134.). By nie mnożyć odniesień, zacytuję znów Giddensa:

Ciało w coraz mniejszym stopniu funkcjonuje poza samozwrotną logiką systemów nowoczesności, jako zewnętrzne i „dane”, a w coraz większym stopniu samo jest refleksyjnie mobilizowane. Wszystko to, co może przypominać masowy pęd ku narcystycznej kultywacji wyglądu ciała, jest w istocie wyrazem dużo głębszej troski o czynne „konstruowanie” i kontrolę nad ciałem. Istnieje tu integralny związek między rozwojem cielesnym a stylem życia, który przejawia się na przykład w poddawaniu ciała specyficznym reżimom. (Giddens 2001, 12).

Efektem projektowania jest zawsze do pewnego stopnia „nienaturalne” ciało. Kultura wirtualności jest kulturą korporealnej sztuczności, czego 
Chelsea Charms jest ewidentnym świadectwem. Sztuczne ciało nie oznacza prostej nieautentyczności wizerunku, rozumianego jako materializacja jak najbardziej realnych pragnień jednostkowych. Twórcą marki nie jest sztuczny byt (silikonowe implanty), ale społeczeństwo działające w kulturowo określonym środowisku kreowania rynkowej tożsamości. Wizerunek jako marka należy zatem traktować raczej jak intersubiektywny proces konstruowania znaczeń, niż jak narzucony z zewnątrz kulturowy kaftan. W tym kontekście kulturowa tożsamość sztucznego ciała nie jest równie jak ono sztuczna, ale wypływa z procesów refleksyjnego ustosunkowywania się do kulturowego kontekstu. Postać, taka jak Chelsea Charms, ucieleśnia liberalny ideał aktywnej egzystencji, biorącej na siebie ciężar odpowiedzialności za własne działania. Choć jej ciało jest w najbardziej istotnym fragmencie sztuczne, jej tożsamość (osobistą i społeczną) nie sposób za taką uznać. Największy biust świata to nie maska ani kostium - nie jest przywdziewany, by zakryć głęboką prawdę o podmiocie. Wręcz przeciwnie, stając w centrum tożsamości jednostkowej i społecznej, sztuczne piersi konstytuują głęboką prawdę egzystencji Charms jako figury afirmującej ideały globalnego przemysłu kulturowego.

Można na Charms, jako osobę, popatrzeć jak na ofiarę patriarchatu, modelowy przykład alienacji. Istnieje jednak także alternatywny punkt widzenia - Charms jako marka staje się w nim świadectwem demokratyzacji życia społecznego w dobie globalnego przemysłu kulturowego. Böhme pewnie podpisałby się właśnie pod tą drugą tezą, skoro stwierdza:

Fetyszyzm stał się kwestią wyboru spośród wielu opcji, jest karnawałowy, a o tyle demokratyczny. $Z$ jednej strony fetysze zwiększają rolę społecznej nieświadomości, z drugiej jednak - czynią ją jawną i zasadniczo otwartą na przemyślenie. W kulturze powszechnej cyrkulacji fetyszy stosunki między nieświadomością i świadomością są mniej napięte, bardziej ludyczne aniżeli w czasach społeczeństwa neurotycznego rozdartego między oświeceniem i represją. (Böhme 2012, 311).

Być może zatem Chelsea Charms, mieniąca się posiadaczką największego biustu świata, rzeczywiście jest tak zadowolona ze swojego wyboru, jak prezentuje to w wywiadach. W końcu jeśli „it’s fun to be different”, mało kto bawi się tak dobrze jak ona. Wydaje się jednak, że na tym nie można zakończyć kulturoznawczej analizy jej przypadku. 


\section{XI}

Coraz częściej i w coraz większej liczbie sfer naszego życia chodzi o kondensację wrażeń, o maksymalizację doświadczenia w sensie Diltheyowskiego Erlebnis. Lash i Lurry precyzyjnie rekonstruują konsekwencje tego dążenia w dziedzinie kultury popularnej: „Właściwe naszej epoce przedmioty kultury to samoorganizujące się systemy, czasami funkcjonalnie zamknięte, czasami zmieniające się w pojedynczości zdolne do przeprowadzania łączących syntez, w wielu miejscach aktualizujące się jako wydarzenie." (Lash i Lury 2011, 29). Sądzę, że Quinn, świadomy rozplenienia się tego typu „przedmiotów", ich kulturowej dominacji, dostrzegł w Charms nie po prostu rzecz, w Lukácsowskim sensie egzystencji zreifikowanej w wyniku dominacji wymiany towarowej (Lukács 1988), ale ikonę kultury współczesnej, jednostkę grającą w skomplikowaną grę na przecięciu materialnej egzystencji i wirtualnej ekonomii, w którą on sam, tak jak wszyscy ludzie aspirujący do statusu podmiotu kultury współczesnej, jest uwikłany.

$\mathrm{Na}$ tak określonym gruncie $\mathrm{w}$ centrum analizy staje fenomen ciała kuriozalnego, rozumianego nie wyłącznie jako sensacja, ale dwoisty konstrukt kulturowy, uruchamiający z jednej strony ciekawość (jak w klasycznym muzeum osobliwości czy dziewiętnastowiecznym American Museum P. T. Barnuma), a z drugiej podziw (jak w dyskursie atletycznym). Ciekawość uprzedmiotawia, podziw wynika $\mathrm{z}$ upodmiotowienia ciała, które $\mathrm{w}$ dobie kultury wirtualizacji podlega istotnemu przewartościowaniu. Jak zauważa Lambert Wiesing: „Wirtualna rzeczywistość dana jest tylko wtedy, kiedy obraz nie służy już jako medium, aby się odnieść do czegoś nieobecnego, ale kiedy obraz staje się medium, za pomocą którego wytwarzany jest i prezentowany szczególny rodzaj przedmiotu - mianowicie przedmiot, który jest tylko widzialny, a mimo to zachowuje się jak widmo, jak gdyby miał jakąś substancję i jej właściwości." (Wiesing 2012, 140). Ciało przestaje być opakowaniem dla tożsamości, jego rolą nie jest odsyłanie do bezcielesnego wnętrza, ale staje się właśnie medium, czyli procesem powoływania do życia wirtualnego przedmiotu zachowującego się jak realny byt: intensywnej raczej niż ekstensywnej marki jako osi tożsamości kulturowej. Analiza figury takiej jak Chelsea Charms pozwala to dostrzec. Zadaniem jednostki, chcącej odgrywać podmiotową rolę w przestrzeni przepływów globalnego przemysłu kultury, jest stworzenie wyrazistej autoreprezentacji, skondensowanej do jednego, względnie kilku wybranych aspektów (kreacja przedmiotu kulturowego). W kolejnym kroku z reprezentacją tą należy się utożsamić, pozbywszy 
się tęsknoty za „prawdą”, która poprzedzała kreację. Chodzi tu o wzbudzenie przekonania, że dopiero reprezentacja mówi prawdę o jednostce, która wyraża samą siebie poprzez uprzedmiotowioną kreację. Proces ten pozwala jednostce nie czuć się produktem narzuconych okoliczności (kultura wirtualizacji jest krytyczna wobec pojęcia „prawdy egzystencji”, rozumianej jako naturalność ciała, rdzeń tożsamości niepodlegający społecznemu konstruktywizmowi, np. chrześcijańska dusza) lecz własnym dziełem sztuki („prawdę” egzystencji zastępuje prawda „reprezentacji”).

Nic dziwnego, że Chelsea Charms skrupulatnie ukrywa swoje „prawdziwe” personalia. Prawdę, czyli to, co przyrodzone, całkowicie zastępuje autorska kreacja, karmiąca się dążeniem do maksymalnej wyrazistości puszczanego w obieg wymian towarowych i symbolicznych wizerunku. By osiągnąć założony cel, konieczne jest możliwie spektakularne wyróżnienie się z tłumu, które ma na celu wzbudzenie w tymże tłumie ciekawości. Efektem jest kuriozalność, którą postrzegam jako kluczowy ideał kultury wizerunku. Ucieleśniona kuriozalność - ciało niekonwencjonalne, acz wzbudzające ciekawość, a nie jedynie wstręt ${ }^{16}$ - nie jest nigdy dziełem stworzonym całkowicie autonomicznie przez jednostkę. Rodzi się w reakcji na kulturowe wymogi. Obserwujemy tu istotną podwójność: materialność, będąca efektem konkretnych operacji na tkankach, zyskuje sens jedynie w oparciu o wyobrażony wzorzec, który ma wirtualny charakter. Ciało kuriozalne jest zawsze zatem podwójne: wirtualne i materialne równocześnie, przy czym przewagę zyskuje ten pierwszy aspekt. W obrębie „logiki kuriozalności” materialność służy fantazmatowi, który ma kulturowy charakter, gdyż nie jest personalną fantazją. Można powiedzieć, że wirtualne ciało Chelsea Charms, którego materialnym interfejsem, swoistym „logo”, są jej silikonowe piersi, jest nieustannie konstytuowane w przestrzeni globalnych kulturowych przepływów. Jak pokazała analiza medialnych opowieści o Charms, fascynacja nie wypływa z seksualnego pożądania (choć można podejrzewać, że dla najbardziej oddanego fandomu jej biust jest atrakcyjny przede wszystkim w seksualnym sensie), ale z podziwu dla czegoś, co nazwałbym zdolnością Charms do „obiektywizacji”, przekształcenia samej siebie w obiekt, do oddania się na usługi

${ }^{16} \mathrm{~W}$ kulturze wizerunku istnieją pewne odmiany ciała monstrualnego, odrażającego, które podlegają procesom wymiany towarowej i symbolicznej, a więc mają charakter jak najbardziej funkcjonalny. Wciąż jednak wydaje się, że istnieją też takie rodzaje ciała (ciało wykazujące zewnętrzne symptomy choroby), które nie sposób uznać za w jakikolwiek sposób atrakcyjne, przynajmniej w obrębie kultury popularnej, nie poddające się zatem procesowi utowarowienia. 
nadmiarowego ciała. W tej perspektywie jawi się ona jako reprezentantka fetyszystycznej nowoczesności, postulującej nieustające orientowanie własnego życia, również w jego jak najbardziej materialnym aspekcie, na wizerunek postrzegany w kategoriach aury. Ostatecznie stawką, o jaką toczy się gra, jest wszak kulturowe uwznioślenie, specyficznie pojmowana transcendencja.

Nie jest niczym zaskakującym ani nowym, że to kultura wyznacza pożądane kierunki cielesnej transformacji. Mogą one mieć na przykład rytualny charakter, gdy w grę wchodzi odniesienie sfery cielesnej do tak czy inaczej pojętego sacrum, jak ma to miejsce w tak zwanych społecznościach tradycyjnych. W tym kontekście ciało poddane transformacji nie staje się kuriozalne, bo modyfikacja ma w zasadzie charakter zwyczajowy, a równocześnie jest legitymizowana przez to, co inherentnie „kuriozalne” (zaciekawiające i godne podziwu), a więc właśnie sferę sakralną. Ale może też być tak - i to jest przypadek współczesnej kultury wizerunku rządzącej się zasadą wirtualizacji że ciało zostaje poddane transformacji w imię samej możliwości jej przeprowadzenia. Proces ten jest całkowicie immanentny, a kuriozalność arbitralnie zdefiniowana. Chodzi nie o transgresję, ale o intensyfikację doświadczenia. Dialektyka wirtualności i materialności nie prowadzi do sakralizacji lecz do całkowitej funkcjonalizacji ciała.

W tym procesie powstają specyficzne, korporealne marki, których podstawowym modus operandi są operacje różnicowania w obrębie określonego przez kulturę pola wymian towarowych i symbolicznych, czy może raczej: towarowo-symbolicznych. Marka „Chelsea Charms” ma sens jedynie w obrębie kulturowo konstruowanej kategorii „kobieta o największych sztucznych piersiach na świecie”, tak samo jak marka „Mariusz Pudzianowski” ma sens jedynie w obrębie kulturowo konstruowanej kategorii „najsilniejszy człowiek na świecie" ${ }^{17}$. Cechą dystynktywną marki są konkretne osiągnięcia jej nosiciela, ale logika konstruowania tożsamości marki w oparciu o maksymalizację, optymalizację osiągnięć jej nosiciela, jest niezależna od jego działań. Podczas gdy nosiciel marki, konkretne ciało, pozostaje materialne,

${ }^{17}$ Oczywiście, istnieją istotne różnice między charakterem osiągnięć Mariusza Pudzianowskiego i Chelsea Charms, niemniej, co dla mnie ważniejsze, obie figury mają atletyczny charakter i obie są przede wszystkim nakierowane na wirtualną rzeczywistość, stając się markami poprzez wirtualizację, dla której cielesne transformacje przez trening lub operacje plastyczne (i konieczny w ich następstwie trening) są jedynie materialną bazą. Ikoniczność Pudziana, podobnie jak Charms, rozgrywa się w świecie wyobrażeń (stał się on celebrytą nie tylko dzięki zawodom strong men, ale przede wszystkim telewizji). 
gwarantując realność marki w tradycyjnym sensie tego słowa, sama marka, wirtualne ciało, konstytuuje się w porządku nadrealności, która zmusza nosiciela do nieustannej, możliwie wytężonej pracy nad podkreślaniem swojej unikatowości. Efektem jest właśnie ciało kuriozalne, wirtualny fetysz, który funkcjonuje jako marka.

\section{Bibliografia}

Adams, Rachel. 2001. Sideshow U.S.A.: Freaks and the American Cultural Imagination. Chicago: University of Chicago Press.

Archer, Margaret. 2013. Człowieczeństwo. Problem sprawstwa. Tłum. Agata Dziuban. Kraków: Nomos.

Bataille, Georges. 2002. Część przeklęta oraz Ekonomia na miarę wszechświata, Granice pożytecznego. Tłum. Krzysztof Jarosz. Warszawa: Wydawnictwo KR.

Bauman, Zygmunt. 1995. Ciało i przemoc w obliczu ponowoczesności. Toruń: Wydawnictwo Naukowe UMK.

Benjamin, Walter. 1996. „Dzieło sztuki w dobie reprodukcji technicznej”. Tłum. Janusz Sikorski. [w:] W. Benjamin, Aniot historii: eseje, szkice, fragmenty, red. Hubert Orłowski, 201-239. Poznań: Wydawnictwo Poznańskie.

Beshine. 2019. „The Official Website of Beshine”. Dostęp: 28.11.2019. http:// www.beshine.com.

Bogdan, Robert. 1990. Freak Show: Presenting Human Oddities for Amusement and Profit. Chicago: University of Chicago Press.

Boobpedia. 2019. „Chelsea Charms”. Dostęp: 28.11.2019. http://www. boobpedia.com/boobs/Chelsea_Charms.

Böhme, Hartmut. 2012. Fetyszyzm i kultura. Inna teoria nowoczesności. Tłum. Mateusz Falkowski. Warszawa: PWN.

Charms, Chelsea. 2010a. „Chelsea Charms OLD Interview”. Wywiad na kanale Boobzie.Channel. Dostęp: 28.11.2019. https:/www.youtube.com/ watch?v=EJiEcArM93M.

2010b. „Chelsea Charms Breasts Interview”. Wywiad na kanale Extremebods1o. Dostęp: 28.11.2019. https://www.youtube.com/watch $? \mathrm{v}=7$ PDnxCe6oAI.

2019a. Twitter profile (@chelseacharmsx). Dostęp: 28.11.2019. https://twitter.com/chelseacharmsx.

2019b. „News \& FAQs”. Dostęp: 28.11.2019. http://www. chelseacharms.com/newsfaq.html. 
Chemers, Michael M. 2008. Staging Stigma: A Critical Examination of the American Freak Show. New York: Palgrave Macmillan.

Durbach, Nadja. 2010. The Spectacle of Deformity: Freak Shows and Modern British Culture. Berkeley, Los Angeles, London: The University of California Press.

Falk, Pasi. 1994. The Consuming Body. London, Thousand Oaks, New Delhi: Sage Publications.

Featherstone, Mike. 2008. Ciało w kulturze konsumpcyjnej. Tłum. Iwona Kurz. [w:] Antropologia ciała. Zagadnienia i wybór tekstów, red. Małgorzata Szpakowska, 109-117. Warszawa: Wydawnictwa Uniwersytetu Warszawskiego.

Giddens, Anthony. 2001. Nowoczesność $i$ tożsamość. „Ұ̈ $i$ spoteczeństwo w epoce późnej nowoczesności. Tłum. Alina Szulżycka. Warszawa: PWN.

Godelier, Maurice. 2010. Zagadka daru. Tłum. Marta Höffner. Kraków: Wydawnictwo Uniwersytetu Jagiellońskiego.

Haraway, Donna. 2003. „Manifest cyborgów: nauka, technologia i feminizm socjalistyczny lat osiemdziesiątych”. Tłum. Sławomir Królak, Ewa Majewska. Przeglad Filozoficzno-Literacki, nr 1(3): 49-87.

Hattenstone, Simon. 2010. „Marc Quinn: Just don't call it a freak show”. The Guardian. Dostęp: 28.11.2019. https://www.theguardian.com/ artanddesign/2010/may/o1/marc-quinn-interview.

Klimczyk, Wojciech. 2008. Erotyzm ponowoczesny. Kraków: Universitas.

Kracauer, Siegfried. 1987. Ornament z ludzkiej masy. Tłum. C. Jenne. [w:] Wobec faszyzmu, red. Hubert Orłowski, 11-23. Warszawa: PIW.

Krzak, Zygmunt. 2007. Od matriarchatu do patriarchatu. Warszawa: Wydawnictwo Trio.

Lash, Scott i Celia Lury. 2011. Globalny przemyst kulturowy. Medializacja rzeczy. Tłum. Jakub Majmurek, Robert Mitoraj. Kraków: Wydawnictwo Uniwersytetu Jagiellońskiego.

Lukács, György. 1988. Historia i świadomość klasowa. Studia o marksistowskiej dialektyce. Tłum. Marek Siemek. Warszawa: PWN.

Ryczek, Justyna. 2006. Piękno w kulturze ponowoczesnej. Kraków: Rabid.

This Morning. 2011. „The Biggest Boobs in the World”. Dostęp: 28.11.2019. https://www.youtube.com/watch?v=TUEkwrK9R3M.

Thomson, Rosemarie Garland, red. 1996. Freakery: Cultural Spectacles of the Extraordinary Body. New York: NYU Press.

Wiesing, Lambert. 2012. Sztuczna obecność. Studia z filozofii obrazu. Tłum. Krystyna Krzemieniowa. Warszawa: Oficyna Naukowa. 


\title{
Abstract, keywords, about the author
}

\begin{abstract}
Chelsea Charms: The curious body as a brand

Chelsea Charms claims that she has the biggest artificial breasts in the world. She is followed by more than 270,00o users on Twitter. Charms gives interviews to the mainstream media. She also runs her own website. Although she has never used her body in hardcore pornography, she is nevertheless a kind of celebrity, very careful about her image, defined, obviously, by her enormous bust.

Charms very clearly identifies herself with her breasts. In the media her breasts are presented as the essence of her personality. In a cultural sense, there is no difference between her image and her bust, allowing us to speak of a peculiar branding, with Charms's breasts serving as a "logo".

In this article I analyse how the media figure of "the woman with the largest (augmented) breasts in the world" comes to life, in relation to Celia Lury and Scott Lash's theory of the global culture industry and Hartmut Boehme's take on the cultural role of fetishism in modernity. I attempt to deconstruct the "Chelsea Charms" brand in the context of contemporary image culture, which feeds on augmented bodies like no other. At the same time, I pose a crucial question: Does having an artificial body automatically lead to having an artificial identity or is the relation between the two much more complex, and by reconstructing it, can one can better understand contemporary strategies of identity building, even outside of this particular case? The answer is paradoxical: because of her curious character, Chelsea Charms can be seen as a model exponent of the culture of virtuality, which is based on the myths of individual agency, creative freedom, and plasticity of human existence, including the body.
\end{abstract}

Keywords: global cultural industry, fetishism, image culture, image, Chelsea Charms, implants, body

Wojciech KLIMCZYK, sociologist by profession, currently more interested in cultural studies, Klimczyk has published diverse works on the body in contemporary culture, including the following books: Postmodern Eroticism, Visionaries of the Body. Panorama of contemporary dance theatre and The Virus of Mobilisation. Dance and the formation 
of modernity $1455^{-1795}$, vol. 1-2. Together with Agata Świerzowska he has edited the anthology Music and Genocide. His doctoral thesis entitled Anthropology of Contemporary Dance Theatre. Dynamics of artistic practice was defended with honours. Currently he is working on the monograph about Vaslav Nijinsky as well as conducting preliminary research for the project Republican Moves. The Dutch Roots of Modern Kinesis.

E-MAIL: wojciech.klimczyk@uj.edu.pl 